\title{
Production and Optimization of Eco-Friendly Composite from KClO3 Treated Date Fiber Reinforced HDPE (high density polyethylene)
}

\author{
Aneke N.A.G1, Egbuna S.O ${ }^{1}$, Ejikeugwu N. $L^{2}$ and Omotiomo $M^{1}$ \\ ${ }^{1}$ Chemical Engineering Department, Enugu State University of Science and Technology, Enugu, Nigeria \\ ${ }^{2}$ Advance Manufacturing unit, Scientific Equipment Development Institute, Enugu, Nigeria \\ DOI: 10.29322/IJSRP.11.06.2021.p11429 \\ http://dx.doi.org/10.29322/IJSRP.11.06.2021.p11429
}

\begin{abstract}
In the study, the untreated and potassium chlorate, $\left(\mathrm{KClO}_{3}\right)$ treated micro sized Date Palm Petiole Fiber, (DPPF) were used to produce natural fiber/HDPE composites by injection molding machine. DPPF was characterized to determine their chemical compositions in terms of cellulose, hemicellulose and lignin. Central Composite Design (CCD) tool of RSM was applied for optimization processes. Analyses of the results showed that cellulose content is, hemicelluloses and lignin. Chemical treatment of the fibers modified and enhanced properties of the fibers. Quadratic model described the relationship between percentage cellulose yield and considered factors of chemical concentration, mass/volume ratio and time. From the three process variables considered, percentage cellulose is $60.3 \%$ at $3.5 \mathrm{wt} \%$ concentration, $4 \mathrm{~g} / \mathrm{l}$ mass/volume ratio and time of $16 \mathrm{hr}$. Quadratic model also described the relationship between tensile strength and process variables of temperature, fiber/polymer ratio and time. The composites produced gave tensile strength 42.0 Mpa fiber/polymer ratio $29 \mathrm{wt} \%$, temperature $172^{\circ} \mathrm{c}$ and time $10 \mathrm{~min}$. The chemical treatment gave a better interfacial bonding of the $\mathrm{DPPF} / \mathrm{HDPE}$ and resulted to increased properties of the composite.
\end{abstract}

Index Terms- Date palm petiole fiber, potassium chlorate, micro size, chemical composition, response surface methodology, Central Composite Design tensile strength

\section{INTRODUCTION}

A composite is a material created out of two or more substances that is stronger and superior to those individuals by themselves. They are always made with a particular property in mind like added strength, efficiency, light weight or durability. Polymeric composites are polymers that have been filled with natural or synthetic compounds as to improve their physical and chemical properties, as well as to reduce cost. Dlamini 2012) stated that fibers are obtained from biomass, forestry and agricultural residues.

Composites from natural fibers are gaining importance due to they are non-carcinogenic, biodegradable and other numerous advantages like Like reduced tool wear, low density per unit volume, acceptable specific volume, low cost and renewable (Jawaid et al 2014). Satyanarayana et al (2009) opined that due to increase in environmental safety and use of renewable materials for a cleaner society, the use of natural fibers to reinforce composites, has attracted so many researchers and industrialists and are also replacing synthetic fiber because of its severe disadvantages like high cost and also create severe ecological and health hazards for the workers. However, the main disadvantages of natural fiber composite are the relative high moisture absorption and poor fiber/matrix interaction . Jawaid et al (2014) mentioned that the low interfacial bonding between highly hydrophilic natural fibers and hydrophobic, non-polar polymer matrix, has resulted to a drop in the properties of the composites and thus hinders their industrial utilization and production. Kalia et al (2009) stated various surface modification techniques which could remedy the problem of low interfacial bonding between the natural fibers and polymer matrix.

Moreover, there are several potential fibers which is available in huge amounts every part of Nigeria like date palm fiber, thus there is need to optimize the production of date palm fiber reinforced high density polyethylene composites.

\section{MATERIALS AND METHODS}

\section{Materials}

Materials used for this study are fiber (SPPF) and High density polyethylene. The polyethylene was purchased from the Indorama Eleme Petrochemicals Limited, Port-Harcourt, Nigeria.

The SPPF were prepared from the petiole of spindle Palm frond by mechanical method. Kengkhetkit and Amornsakchai (2012) noted that fibers can be decorticated without significant damage and can be produced with high quality, even when no pretreatments are carried out. The extraction of the fiber was done by decortications /traumatizing of the petiole as described by Deyholos and Potter 
(2014). The fibers extracted were then cleaned, washed thoroughly with distilled water that removed most of the impurities and then sun dried for two days.

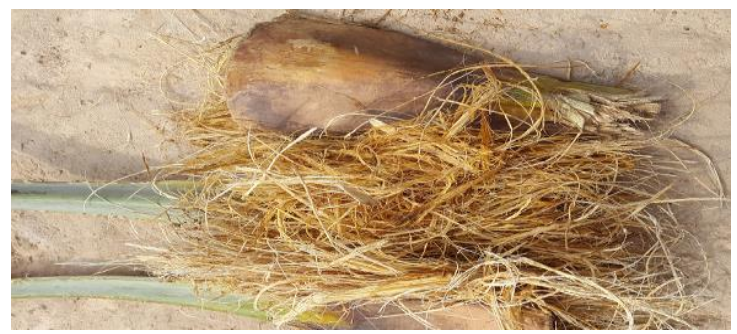

Figure1: Date palm petiole with the mechanically extracted date palm petiole fiber (DPPF)

\section{Surface modification}

The treatment with potassium chlorate was done based on the method used by Nadanthangam et al, 2013, with slight modification. The fibers were soaked in different weight percent of $\mathrm{KClO}_{3}$ solution at different duration. Thereafter, they were washed with distilled

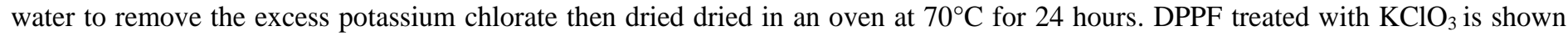
Figure 2.

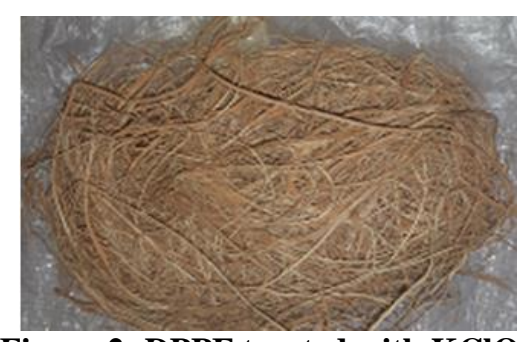

Figure 2: DPPF treated with $\mathrm{KClO}_{3}$

\section{Characterization}

The chemical composition of DPPF was determined using TAPPI Standard Test Method T204 cm-17 for extractives, TAPPT Standard Test Method T203 cm-99 for $\alpha$ cellulose and lignin content by TAPPI Standard Test Method T222.

Fourier transform infrared (FTIR) spectroscopic analysis was done with Buck scientific M530 USA. The morphology of DPPF was carried out with JEOL JSM 7500F Scanning Electron Microscope (SEM).

The DPPF was pulverized with a laboratory mill made by Christy and Norris Ltd, Chelmsford, England.

\section{Determination of effects of process variables}

Effects of process variables on the chemical composition of the fibers were determined considering variables: concentration of the chemicals, the mass/ volume ratio of the chemicals and time. Also the effects of process variables on the mechanical properties of the composites were determined by varying the effect of fiber/polymer ratio, temperature and time.

\section{Optimization}

Central Composite Design (CCD) tool of Response Surface Methodology (RSM) was applied in determining interactive effects of the variables on cellulose and tensile strength. The RSM experimental data was analyzed using analysis of variance (ANOVA), fit statistics, mathematical modeling and graphical plots. Optimum response was obtained was validated.

\section{Composites Production}

The DPPF, HDPE and coupling agent (Maleic Anhydride Polyethylene - MAPE) were mixed physically in a bowl and then poured into injection molding machine where the proper mixing and melting occurred. The mechanical test samples were formed inside the molds produced with vertical milling center CNC. Then a press was used for compression process. $2 \%$ of MAPE was used for the composite production.

\section{Test procedures}

Universal Testing Machine (Testometric 2500kgf Rochdale England of serial no 52978 was used for mechanical properties of the composites at cross-head speed of $50 \mathrm{~mm} / \mathrm{min}$ according to ASTM D638 for tensile strength, ASTM D790 for flexural test at standard laboratory atmosphere. 


\section{RESULTS AND DISCUSSION}

\section{Functional groups of DPPF}

The functional groups of untreated and $\mathrm{NaOH}$ treated SPPF is shown in figure $7 \mathrm{a}$ and $\mathrm{b}$. The result of untreated DPPF showed peak at $3200 \mathrm{~cm}^{-1}$ corresponding to hydroxyl stretching vibrations in hemicelluloses and/or cellulose. The peak at $1700 \mathrm{~cm}^{-1}$ corresponds to carbonyl group from either carboxylate groups or ester linkages in pectin. The peak located at $1600 \mathrm{~cm}^{-1}$ wave number belongs to $\mathrm{C}=\mathrm{C}$ bonds or aromatic bonds from lignin. But when the intensities of untreated and treated were compared, it was observed that there were structural changes and increase in the vibrations after chemical treatment. Some of the lignin and hemicelluloses have been removed thereby exposing more of the hydroxyl group in the cellulose making the active sites in the fiber ready for reactions. The peak at $1700 \mathrm{~cm}^{-1}$ in untreated DPPF disappeared in the treated fibers. Chemical treatment reduced hydrogen bonding due to removal of the hydroxyl groups by reacting with the chemicals. This is in agreement with the reports of (Skreekala et al 2000; Abidi and Herath , 2017). The peak located at $1600 \mathrm{~cm}^{-1}$ belongs to $\mathrm{C}=\mathrm{C}$ bonds or aromatic bonds from lignin decreased in treated fibers.

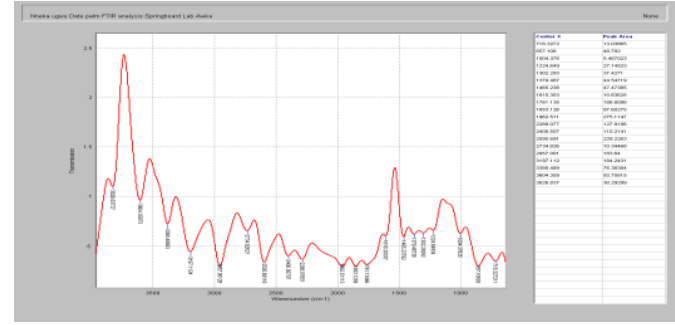

$\mathbf{a}$

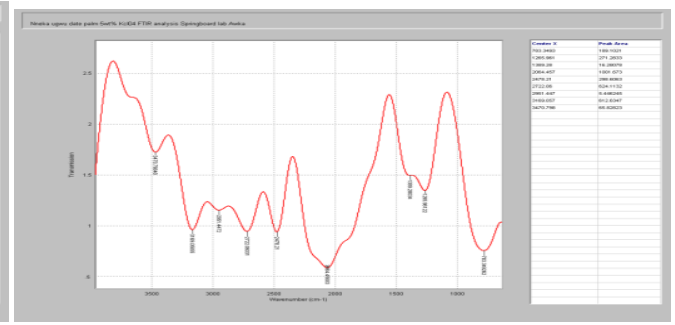

b

Figure 7: FTIR Spectroscopic Analysis of (a) untreated DPPF (b) KClO3 treated DPPF

\section{Morphology}

The micrographs of the SEM of $\mathrm{KClO}_{3}$ - treated DPPF is presented in Plate 1. It is observed that the untreated DPPF has presence of wax, oil, and surface impurities but that of $\mathrm{KClO}_{3}$ - treated DPPF micrographs shows successful removal of the surface contaminants. Also $\mathrm{KClO}_{3}$ - treated DPPF shows exposed surface readily available to react with the matrix (HDPE) more than the untreated DPPF

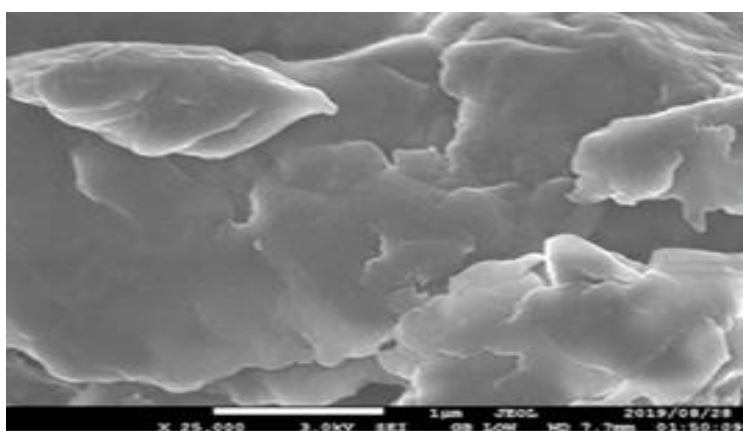

a

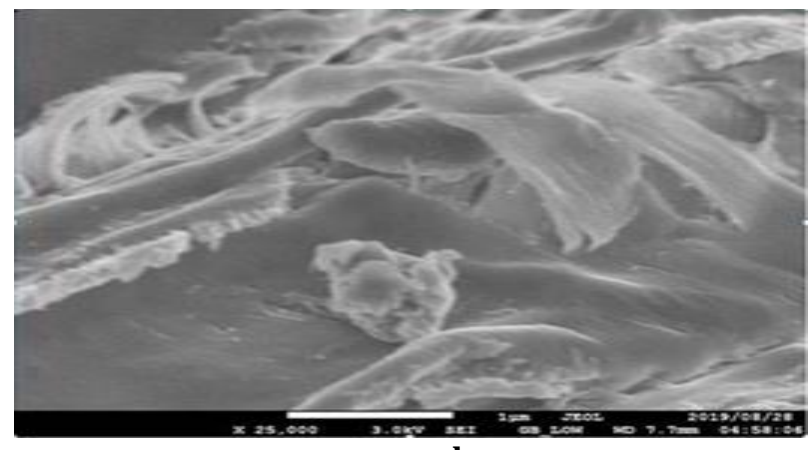

b

Plate 1: a Plate SEM of untreated DPPF b SEM of DPPF treated with $\mathrm{KClO}_{3}$

\section{Particle size reduction to micro size}

The average range of micro particles obtained is $150 \mu \mathrm{m}$ after several grinding and sieving.

\section{Chemical composition of the fiber.}

It was observed from the result that chemical composition of the $\mathrm{KClO}_{3}$ - treated DPPF is higher than the untreated. The untreated DPPF has cellulose $(41.21 \%)$, hemicelluloses $(32.71 \%)$ and lignin $(22.35 \%)$ while the $\mathrm{KClO}_{3}-$ treated DPPF has cellulose $(67.1 \%)$, hemicelluloses (17\%) and lignin $(12 \%)$ as the concentration of $\mathrm{KClO}_{3}$ is increased though the Chemical composition varied at different conditions. This shows that $\mathrm{KClO}_{3}$ has a high extractive property. 


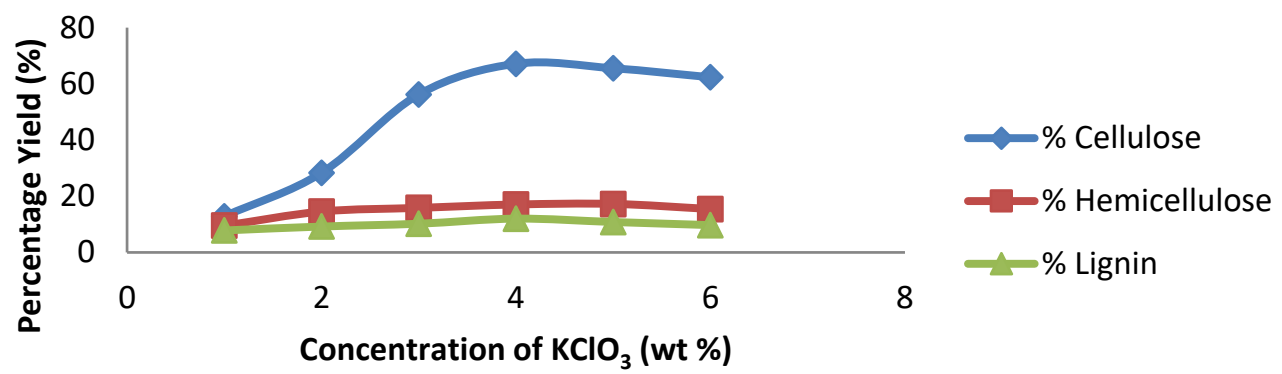

Figure 3: Yield versus concentration of Potassium Chlorate for the treated DPPF

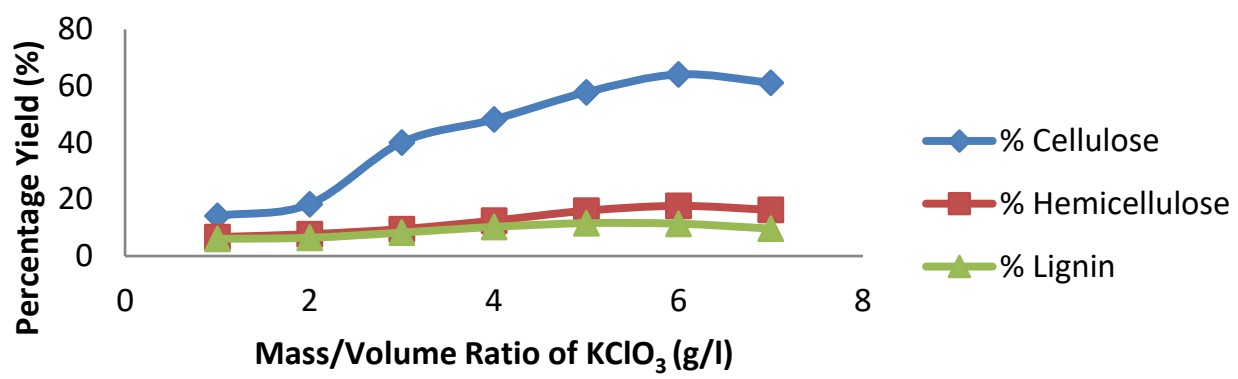

Figure 4: Yield versus Mass/Volume ratio of Potassium chlorate for the treated DPPF

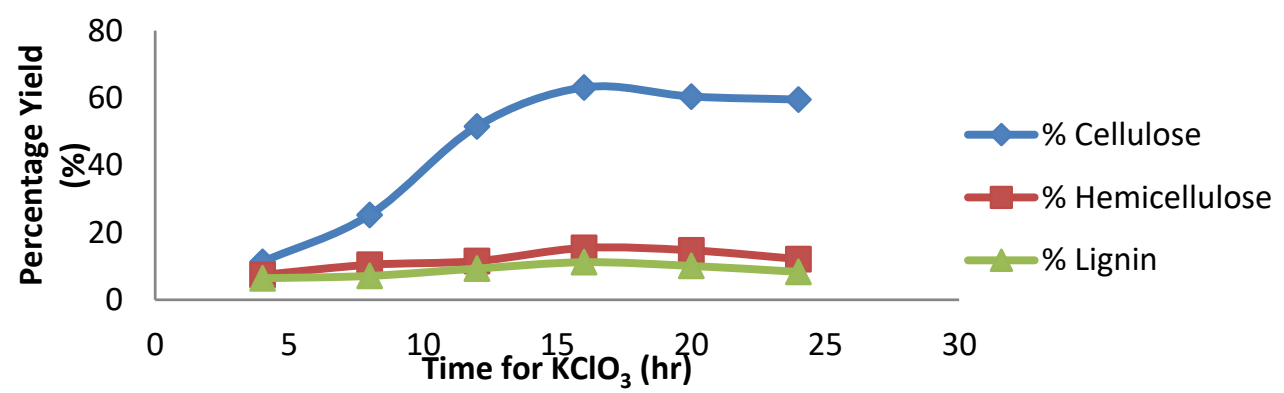

Figure 5: Yield versus Time of Potassium Chlorate for the treated DPPF

\section{RSM Results of Percentage Cellulose}

The RSM results of percentage cellulose of DPPF treated with $\mathrm{KClO}_{3}$ is presented on Table 1. It showed the trend of increased percentage cellulose with increase in considered factors till the optimum point of cellulose $60.3 \%$, concentration $3.5 \mathrm{wt} \%$, mass/volume ratio $4 \mathrm{~g} / \mathrm{l}$ and time $16 \mathrm{hr}$ is reached. The nature of the effect of the interactions among the factors on the cellulose yield can be revealed through analysis of the experimental data. Such analysis include: analysis of variance, fit statistics, diagnostic and 3D plots.

Table 1 RSM Results of DPPF treated with Potassium Chlorate $\left(\mathrm{KClO}_{3}\right)$

\begin{tabular}{|l|l|l|l|l|l|}
\hline Std & Run & $\begin{array}{l}\text { A: Concentration } \\
\mathrm{wt} \%\end{array}$ & B:Mass/Volume Ratio, g/L & $\begin{array}{l}\text { C: Time } \\
\mathrm{Hr}\end{array}$ & Percentage Cellulose, \% \\
\hline 5 & 1 & 2 & 2 & 24 & 29.2 \\
\hline 14 & 2 & 3.5 & 4 & 24 & 54.5 \\
\hline 12 & 3 & 3.5 & 6 & 16 & 64.0 \\
\hline 11 & 4 & 3.5 & 2 & 16 & 34.7 \\
\hline 13 & 5 & 3.5 & 4 & 8 & 57.2 \\
\hline 8 & 6 & 5 & 6 & 24 & 45.1 \\
\hline 20 & 7 & 3.5 & 4 & 16 & 60.3 \\
\hline 2 & 8 & 5 & 2 & 8 & 13.7 \\
\hline 3 & 9 & 2 & 6 & 8 & 50.2 \\
\hline 1 & 10 & 2 & 2 & 8 & 12.1 \\
\hline 9 & 11 & 2 & 4 & 16 & 53.4 \\
\hline
\end{tabular}




\begin{tabular}{|l|l|l|l|l|l|}
\hline 7 & 12 & 2 & 6 & 24 & 55.0 \\
\hline 4 & 13 & 5 & 6 & 8 & 45.2 \\
\hline 10 & 14 & 5 & 4 & 16 & 40.5 \\
\hline 16 & 15 & 3.5 & 4 & 16 & 60.3 \\
\hline 17 & 16 & 3.5 & 4 & 16 & 60.3 \\
\hline 15 & 17 & 3.5 & 4 & 16 & 60.3 \\
\hline 19 & 18 & 3.5 & 4 & 16 & 60.3 \\
\hline 6 & 19 & 5 & 2 & 24 & 15.4 \\
\hline 18 & 20 & 3.5 & 4 & 16 & 60.3 \\
\hline
\end{tabular}

\section{Analysis of variance (ANOVA) and fit Statistics}

The ANOVA and fit statistics of the percentage cellulose of DPPF treated with $\mathrm{KClO}_{3}$ is presented on Table 2. The Model Fvalue of 98.86 implies the model is significant.

Table 2: ANOVA and Fit statistics of percentage cellulose in DPPF treated with $\mathrm{KClO}_{3}$

\begin{tabular}{|c|c|c|c|c|c|c|}
\hline Source & Sum of Squares & $\mathrm{df}$ & Mean Square & F-value & $p$-value & \\
\hline Model & 5426.92 & 9 & 602.99 & 98.86 & $<0.0001$ & Significant \\
\hline A-Concentration & 162.89 & 1 & 162.89 & 26.71 & \begin{tabular}{|l|}
0.0004 \\
\end{tabular} & \\
\hline B-Mass/Volume Ratio & 2395.07 & 1 & 2395.07 & 392.69 & $<0.0001$ & \\
\hline C-Time & 41.78 & 1 & 41.78 & 6.85 & 0.0257 & \\
\hline $\mathrm{AB}$ & 0.6845 & 1 & 0.6845 & 0.1122 & 0.7446 & \\
\hline $\mathrm{AC}$ & 53.35 & 1 & 53.35 & 8.75 & 0.0143 & \\
\hline $\mathrm{BC}$ & 23.60 & 1 & 23.60 & 3.87 & 0.0775 & \\
\hline $\mathrm{A}^{2}$ & 447.24 & 1 & 447.24 & 73.33 & $<0.0001$ & \\
\hline $\mathrm{B}^{2}$ & 294.74 & 1 & 294.74 & 48.32 & $<0.0001$ & \\
\hline $\mathrm{C}^{2}$ & 40.82 & 1 & 40.82 & 6.69 & 0.0271 & \\
\hline Residual & 60.99 & 10 & 6.10 & & & \\
\hline Lack of Fit & 60.99 & 5 & 12.20 & & & \\
\hline Pure Error & 0.0000 & 5 & 0.0000 & & & \\
\hline Cor Total & 5487.91 & 19 & & & & \\
\hline Std. Dev. & 2.47 & & \multicolumn{3}{|l|}{$\mathrm{R}^{2}$} & 0.9889 \\
\hline Mean & 46.58 & & \multicolumn{3}{|l|}{ Adjusted $\mathrm{R}^{2}$} & 0.9789 \\
\hline C.V. \% & 5.30 & & \multicolumn{3}{|l|}{ Predicted $\mathrm{R}^{2}$} & 0.8725 \\
\hline & & & \multicolumn{3}{|l|}{ Adeq Precision } & 30.0519 \\
\hline
\end{tabular}

P-values less than 0.0500 indicate model terms are significant. A, B, C, AC, $\mathrm{A}^{2}, \mathrm{~B}^{2}, \mathrm{C}^{2}$ are significant model terms and concentration, mass/volume ratio and time were responsible for the quadratic nature of the model.

\section{Mathematical model}

The mathematical model of percentage cellulose as a function of treatment factors in terms of significant term is presented in Equations 1. The percentage cellulose was dependent on concentration, mass/volume ratio and time. It is a quadratic model (the highest power of the variables is two).

Percentage Cellulose $=+60.06-4.04 \mathrm{~A}+15.48 \mathrm{~B}+2.04 \mathrm{C}-2.58 \mathrm{AC}-12.75 \mathrm{~A}^{2}-10.35 \mathrm{~B}^{2}-3.85 \mathrm{C}^{2}$

\section{Graphical Analysis of the Percentage Cellulose}

The graphical analyses of the percentage cellulose of treated DPPF are shown in Figure 6. Figure 6a is a plot of the predicted values versus actual values of the percentage cellulose. The points clustered along the line of best fit, which indicated that the generated model adequately predicted the actual yield of the cellulose. In Figures $6 \mathrm{~b}, \mathrm{c}$ and $\mathrm{d}$ are $3 \mathrm{D}$ plots of $\%$ cellulose as a function concentration and mass/volume ratio; concentration and time and lastly, mass/volume ratio and time respectively. \% cellulose increased with increase in all the factors until it got to the optimal points \% cellulose (63.85\%), time (16.92hr), concentration (3.75 wt $\%)$ and mass/volume ratio $(4.57 \mathrm{~g} / \mathrm{l})$. 

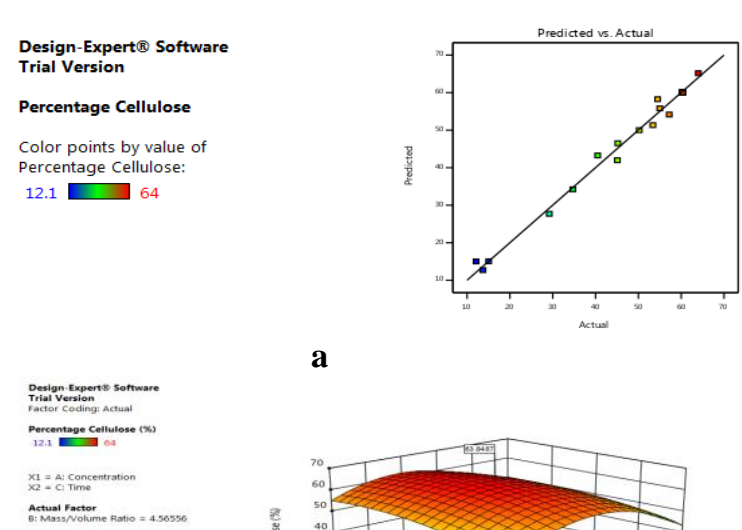

a

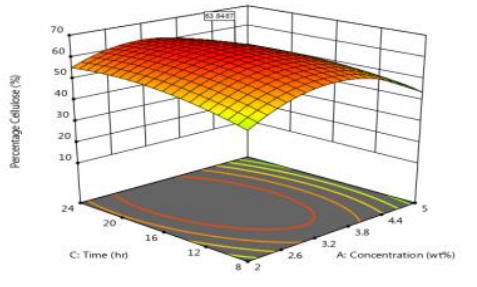

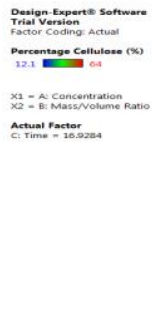
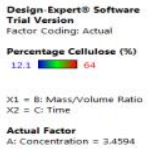

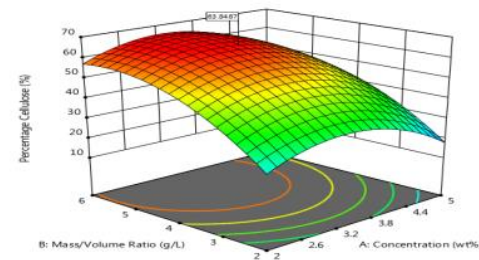

b

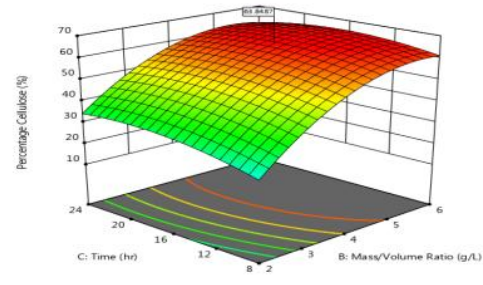

d

Figure 6: a Predicted Versus Actual percentage, b Percentage cellulose versus Concentration and mass/volume ratio, c Percentage cellulose versus Concentration and Time and $\mathrm{d}$ Percentage cellulose versus Mass/Volume ratio and Time for the DPPF treated with $\mathrm{KClO}_{3}$.

\section{Validation of results}

The results of the predicted \% cellulose at optimal condition were validated by comparing them with the experimental results using percentage deviation. The deviation is less than $5 \%$. This showed that the model adequately predicted the percentage cellulose of each of the treated fibers.

\section{Water absorption rate}

The water absorption rates of the composites made with both treated and untreated DPPF are presented in figure 7. It was observed that the water absorbed by the composites made with untreated fibers was high compared to the chemically treated fiber composites. This might be due to possible removal of hemicelluloses during the chemical treatment resulting to a more hydrophobic fiber as hemicelluloses is the most hydrophilic component of fiber (Saheed and Jog 1999). It might also be due to better interfacial bonding of DPPF/HDPE after the chemical treatment. Chemicals activate the hydroxyl groups or introduce new molecules of the fibers that can effectively bond with the matrix (Ali et al 2017).

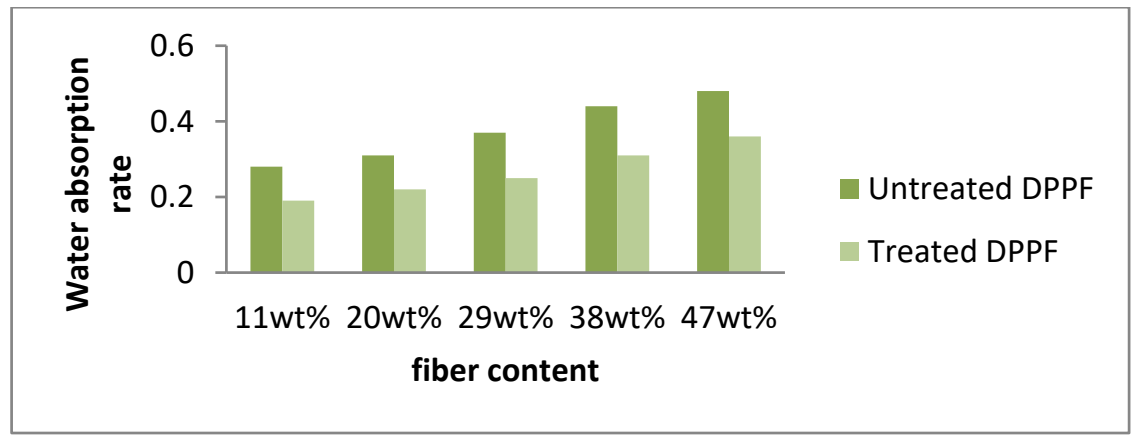

Figure 7: Effect of fiber/polymer ratio on water absorption rate of the composites.

\section{Mechanical properties of the composites}

\section{Effect of Fiber/polymer ratio on tensile strength of the composites}

Effects of fiber content on the tensile strength of composites produced with untreated fibers are presented on Figure 8. It is seen that as the fiber content increases, tensile strength increased till after $29 \mathrm{wt} \%$ of fiber content, then there was a decrease in tensile strength 
of the composites. This might be due to high fiber weight fractions that can lead to fiber-fiber contact, which results in inefficient fibermatrix bonding and a lower stress transfer between fibers and the matrix (Al-Khanbashi et al 2005).

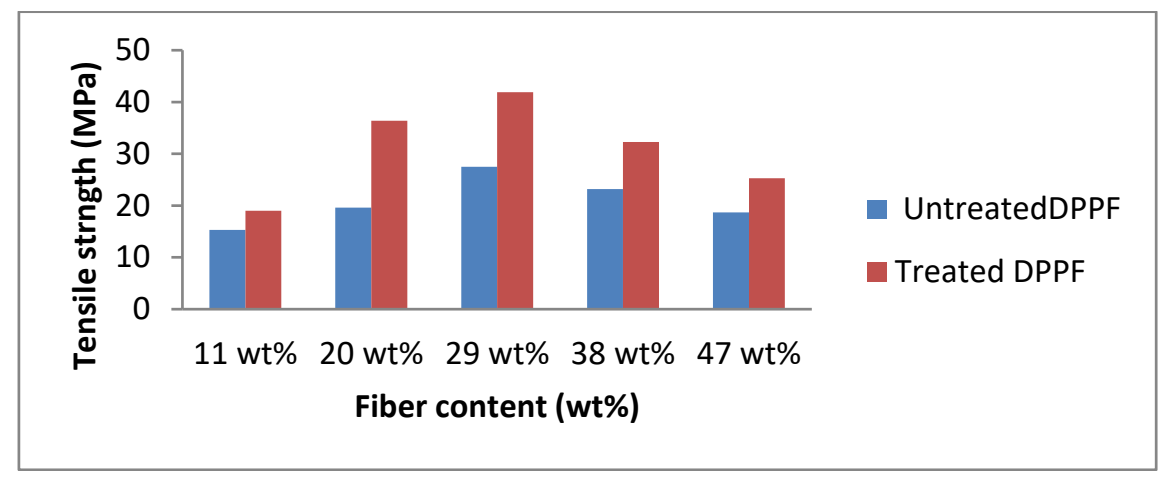

Figure 8: Effect of fiber/polymer ratio on the tensile strength of the composites.

\section{Effect of Temperature on the tensile strength of the composites.}

Effect of Temperature on the tensile strength of composites of chemically-treated and untreated fibers is shown in figure 9. It was observed that the tensile strength increased with increase in temperature till $172^{\circ} \mathrm{C}$ then a decrease occurred with further increase in temperature. Maximum tensile strength of the composite is $41.9 \mathrm{MPa}$. This might be as a result of burning of the fiber at a high temperature which affects the mechanical properties of the fibers. At high temperatures, there is degradation of natural fibers. This is agreement with the reports of Kumarasamy et al (2018) and Singh et al (2018). Siaotong et al, (2010) opined that the optimum value of temperature is very important because lower temperatures result in inconsistent melt of resin that can lead to non-uniform dispersion of the fibers in the composites, which eventually lower the tensile strength.

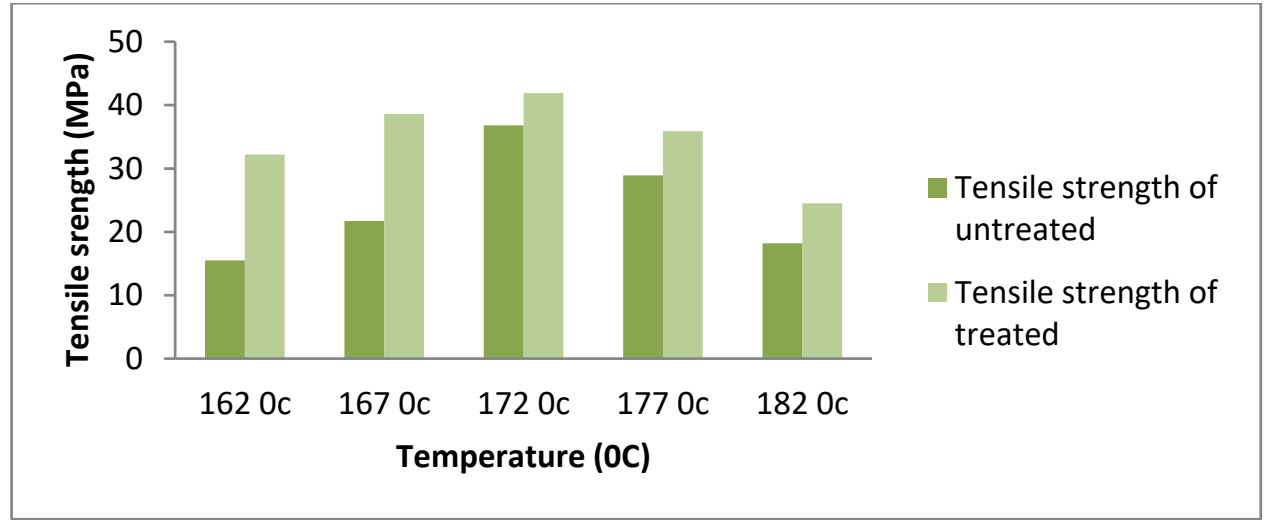

Figure 9: Effect of Temperature on the tensile strength of the composites.

\section{Effect of Time on the Tensile strength the composites.}

Effect of time on the tensile strength is presented on Figures 10. It was observed that tensile strength increased as time increases till 10 minutes before it started reducing. This might be as a result of the fiber staying long in the injection machine, then degradation of the fiber sets in resulting to low mechanical properties of the composites. This is in agreement with the work of Hart and Summerscales (2017). 


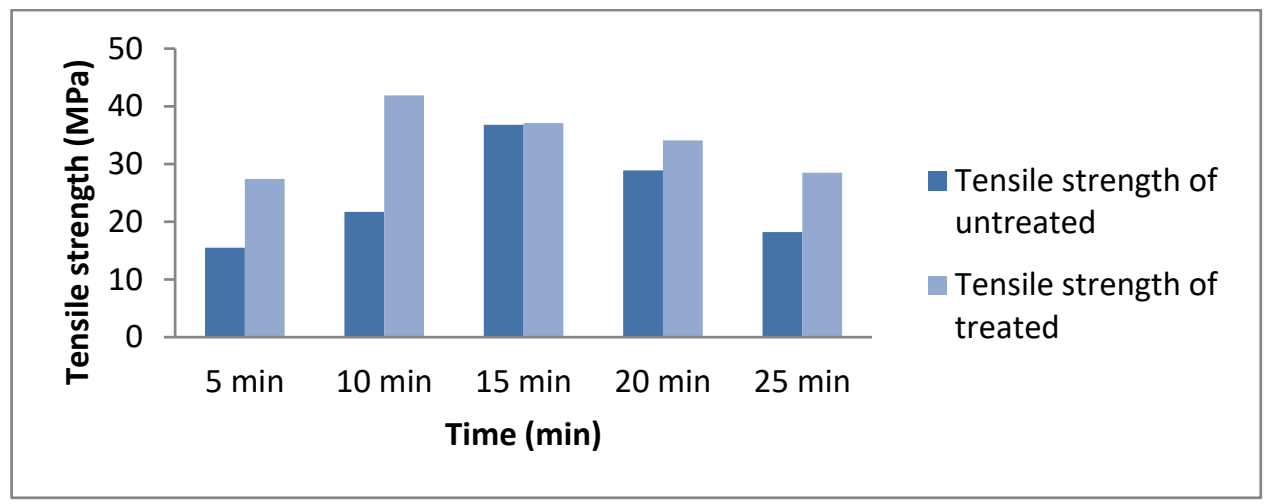

Figure 10: Effect of Time on the Tensile strength of the composite.

\section{Effect of fiber/polymer ratio on the Flexural strength}

Flexural strength of untreated and treated composites at various fibre contents is presented in figures 11 . The flexural strength of DPPF/HDPE composite increased with increase in fiber content up to $29 \mathrm{Wt} \%$, then decrease in flexural strength was seen with higher fiber contents. The reduction could be as a result of inadequate filling of HDPE resin into the SPPF during production of the composites and then fibre/fibre interaction instead of fibre/matrix interaction. This is similar to the results of Herrera-Franco and Valadez-Gonzalez (2005); Bledzki et al (2007) on increased flexural strength as a result of addition of fiber content.

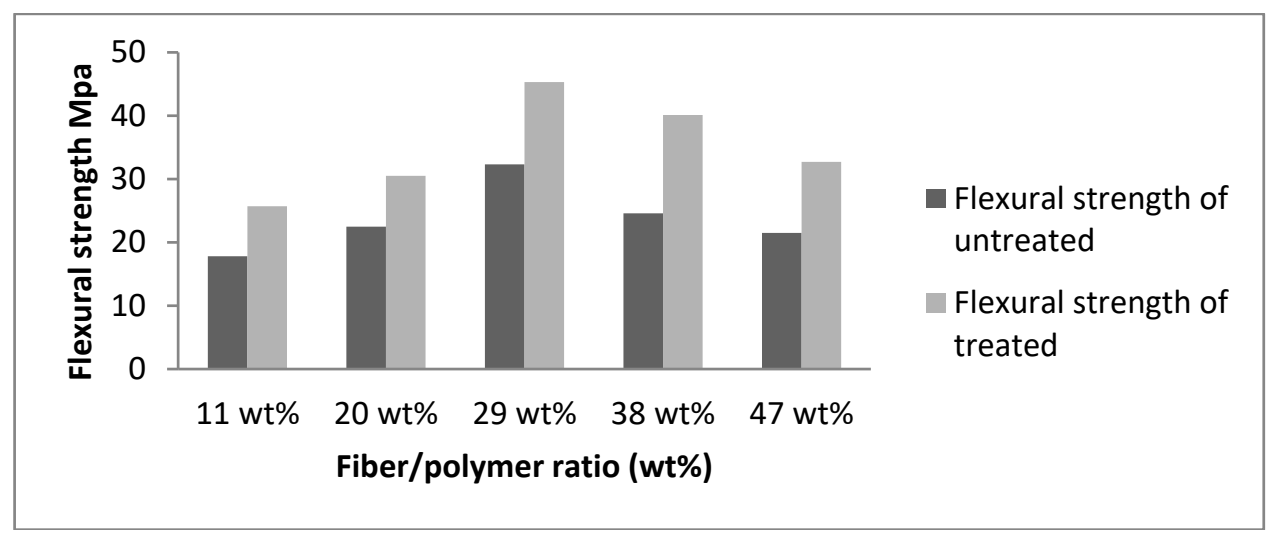

Figure 11: Effect of fiber/polymer ration on the Flexural strength of the composite.

RSM results on the Tensile Strength of the Composites

Effects of process variables on the tensile strength of the composites

The RSM results of Tensile strength of $\mathrm{KClO}_{3}$ treated DPPF composite is shown on Tables 3 . The tensile strength varied with interactive factors of temperature, fiber/polymer ratio and time. It showed the trend of increased tensile strength with increase in considered factors till the maximum point was reached. The nature of the effect of the interactions among the factors on the tensile strength can be seen through analysis of the experimental data. Such analysis include: analyses of variance, diagnostic and 3D plots.

Table 3: RSM Results of DPPF composites treated with Potassium Chlorate

\begin{tabular}{|l|l|l|l|l|l|}
\hline Std & Run & $\begin{array}{l}\text { A: Fibre/Polymer Ratio } \\
\text { wt\% }\end{array}$ & $\begin{array}{l}\text { B: Temperature } \\
{ }^{\circ} \mathrm{C}\end{array}$ & $\begin{array}{l}\text { C: Time } \\
\text { min. }\end{array}$ & $\begin{array}{l}\text { Tensile strength } \\
\text { Mpa }\end{array}$ \\
\hline 5 & 1 & 20 & 167 & 15 & 18.6 \\
\hline 10 & 2 & 38 & 172 & 10 & 32.3 \\
\hline 4 & 3 & 38 & 177 & 5 & 25.4 \\
\hline 1 & 4 & 20 & 167 & 5 & 13.7 \\
\hline 13 & 5 & 29 & 172 & 5 & 34.1 \\
\hline 14 & 6 & 29 & 172 & 15 & 37.1 \\
\hline 7 & 7 & 20 & 177 & 15 & 17.2 \\
\hline 19 & 8 & 29 & 172 & 10 & 42.7 \\
\hline 6 & 9 & 38 & 167 & 15 & 19.2 \\
\hline 8 & 10 & 38 & 177 & 15 & 25.8 \\
\hline
\end{tabular}




\begin{tabular}{|c|c|c|c|c|c|}
\hline 11 & 11 & 29 & 167 & 10 & 32.2 \\
\hline 20 & 12 & 29 & 172 & 10 & 42.7 \\
\hline 9 & 13 & 20 & 172 & 10 & 25.4 \\
\hline 2 & 14 & 38 & 167 & 5 & 16.0 \\
\hline 17 & 15 & 29 & 172 & 10 & 42.7 \\
\hline 15 & 16 & 29 & 172 & 10 & 42.7 \\
\hline 3 & 17 & 20 & 177 & 5 & 16.7 \\
\hline 12 & 18 & 29 & 177 & 10 & 38.6 \\
\hline 18 & 19 & 29 & 172 & 10 & 42.7 \\
\hline 16 & 20 & 29 & 172 & 10 & 42.7 \\
\hline
\end{tabular}

\section{Analysis of variance (ANOVA) and fit Statistics of Tensile strength of the composites}

The ANOVA and fit statistics of the tensile strength of composites of DPPF treated with $\mathrm{KCLO}_{3}$ is presented on Table 4. The Model F-value of 191.26 implies that the model is significant.

Table 4 ANOVA and Fit statistics of Tensile strength in DPPF treated with $\mathrm{KClO}_{3}$

\begin{tabular}{|c|c|c|c|c|c|c|}
\hline Source & Sum of Squares & Df & Mean Square & F-value & p-value & \\
\hline Model & 2211.57 & 9 & 245.73 & 191.26 & $<0.0001$ & Significant \\
\hline A-Fibre/Polymer & 73.44 & 1 & 73.44 & 57.16 & $<0.0001$ & \\
\hline B-Temperature & 57.60 & 1 & 57.60 & 44.83 & $<0.0001$ & \\
\hline C-Time & 14.40 & 1 & 14.40 & 11.21 & 0.0074 & \\
\hline $\mathrm{AB}$ & 25.92 & 1 & 25.92 & 20.17 & 0.0012 & \\
\hline $\mathrm{AC}$ & 0.4050 & 1 & 0.4050 & 0.3152 & 0.5869 & \\
\hline $\mathrm{BC}$ & 6.48 & 1 & 6.48 & 5.04 & 0.0485 & \\
\hline $\mathrm{A}^{2}$ & 407.18 & 1 & 407.18 & 316.92 & $<0.0001$ & \\
\hline $\mathrm{B}^{2}$ & 86.80 & 1 & 86.80 & 67.56 & $<0.0001$ & \\
\hline $\mathrm{C}^{2}$ & 80.73 & 1 & 80.73 & 62.83 & $<0.0001$ & \\
\hline Residual & 12.85 & 10 & 1.28 & & & \\
\hline Lack of Fit & 12.85 & 5 & 2.57 & & & \\
\hline Pure Error & 0.0000 & 5 & 0.0000 & & & \\
\hline Cor Total & 2224.42 & 19 & & & & \\
\hline Std. Dev. & 1.13 & \multicolumn{2}{|l|}{$\mathrm{R}^{2}$} & \multicolumn{3}{|l|}{0.9942} \\
\hline Mean & 30.43 & \multicolumn{2}{|c|}{ Adjusted $\mathrm{R}^{2}$} & \multicolumn{3}{|l|}{0.9890} \\
\hline C.V.\% & 3.73 & \multicolumn{2}{|c|}{ Predicted $\mathrm{R}^{2}$} & \multicolumn{3}{|l|}{0.9680} \\
\hline & & \multicolumn{2}{|c|}{ Adeq Precision } & \multicolumn{3}{|l|}{35.9819} \\
\hline
\end{tabular}

P-values less than 0.0500 indicate model terms are significant. In this case $\mathrm{A}, \mathrm{B}, \mathrm{C}, \mathrm{AB}, \mathrm{A}^{2}, \mathrm{~B}^{2}, \mathrm{C}^{2}$ are significant model terms. From the significant model terms, all the three factors - temperature, fiber/polymer ratio and time were responsible for the quadratic nature of the model.

\section{Mathematical models for the composites}

The mathematical model in terms of significant terms is presented in Equation 4.13 from the equation it shows that the tensile strength was dependent on temperature, fiber/polymer ratio and time. It is quadratic models with the highest power of the variables being two.

The Equation for the tensile strength for composites of DPPF treated with $\mathrm{KClO}_{3}$ is

Tensile strength $=+42.03+2.71 \mathrm{~A}+2.40 \mathrm{~B}+1.20 \mathrm{C}+1.80 \mathrm{AB}-0.9000 \mathrm{BC}-12.17 \mathrm{~A}^{2}-5.62 \mathrm{~B}^{2}-5.42 \mathrm{C}^{2}$

\section{Graphical Analysis for the Composites}

The graphical analyses of the tensile strength of composites with treated DPPF are shown in Figure 12. Figure 12a is a plot of the predicted values versus actual values of the tensile strength of the composite. The points clustered along the line of best fit, which indicated that the generated model adequately predicted the actual tensile strength. Figures $12 \mathrm{~b}, \mathrm{c}$ and $\mathrm{d}$ are $3 \mathrm{D}$ plots of tensile strength as a function of the interactions between the factors: temperature and fiber/polymer ratio; time and fiber/polymer ratio and lastly, time and fiber/polymer ratio respectively. The tensile strength increased with increase in all the factors until it got to a peak which is the optimal point. An optimal tensile strength of $42.03 \mathrm{MPa}$ was obtained at optimal time of $10 \mathrm{~min}$, optimal temperature of $172^{\circ} \mathrm{C}$ and optimal fiber/polymer ratio of $29 \mathrm{wt} \%$. 

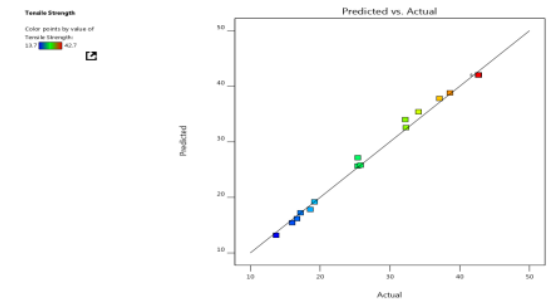

$\mathbf{a}$
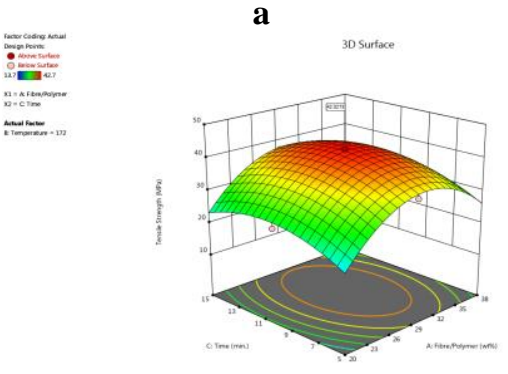

c
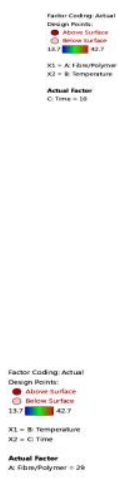

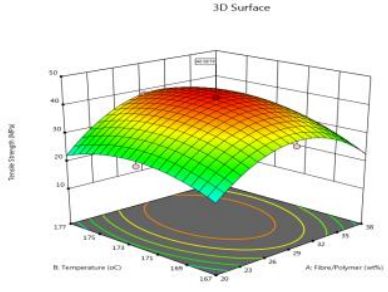

$\mathbf{b}$

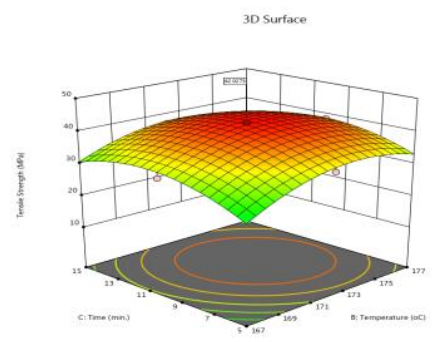

d

Figure12 a Predicted versus Actual Tensile Strength, b Tensile strength versus Temperature and Fiber/Polymer ratio, c Tensile strength versus Time and Fiber/Polymer ratio and $d$ Tensile strength versus Time and Temperature ratio of DPPF treated $\mathrm{KClO}_{3}$ fiber composites.

\section{CONCLUSIONS}

DPPF/HDPE composite was produced and optimized with cellulose content of $65.37 \%$ and tensile strength of 42.0 was produced. The $\mathrm{KClO}_{3}$ treatment on DPPF improved the properties of the composites produced. The results of optimum conditions were validated by comparing them with the experimental results and the Percentage deviation was less than 5\%. The generated models can also serve as a good starting basis for further experimentation in this area.

\section{REFERENCES}

[1] Abidi N. and Herath M. (2017). X-ray diffraction and FTIR investigations of cellulose deposition during cotton fiber development. Textile research journal 88(7) :004051751668863.

[2] Ali N., Din N., Khalid F. S., Shahidan S., Abdullah S. R., Samad A.A.A., and Mohamad N. (2017). Compressive strength and initial water absorption rate for cement brick containing high-density polyethylene as a substitutional material for sand. Mater. Sc. \& engineering 271012083.

[3] Al-Khanbashi A, Al-Kaabi K, and Hammami A (2005) Date palm fibers as polymeric matrix reinforcement: fi ber characterization. Polym Compos 26:486-497.

[4] ASTM D638 - 14. Standard Test Methods for Tensile prop[erties of plastics

[5] ASTM D790 - 17 Standard test Methods for flexural properties of unreinforced and reinforced plastics and electrical insulating materials.

[6] Bledzki, A. K.; Mamun, A. A.; Faruk, O. (2007). Abaca fibre reinforced PP composites and comparison with jute and flax fibre PP composites. Express Polym. Lett. $1,755-762$.

[7] Deyholos M. K, and Potter S. (2014) Engineering bast fiber feedstocks for use in composite materials. Biocatal Agric Biotechnol 3:53-57.

[8] Dlamini Derrick Sibusiso (2012). Polymer composites and Nanofiltration membranes and their application in water treatment, University of Johannesburg, 538 pages.

[9] Herrera-Franco, P. J.; Valadez-Gonzalez A. (2005). A study of the mechanical properties of short natural-fiber reinforced composites. Compos. Part B Eng. 2005, 36, 597-608.

[10] Jawaid Mohammad; Naheed Saba and Paridah Md Tahir (2014) A Review on Potentiality of Nano Filler/Natural Fiber Filled Polymer Hybrid Composites Polymers 2014, 6, 2247- 2273; doi:10.3390/polym6082247.

[11] Kalia S, Kaih BS, Kaur I. (2009) Pretreatments of natural fibers and their application as reinforcing material in polymer composites - a review. Polym Eng Sci ;49(7):1253-72.

[12] Kengkhetkit N. and Amornsakchai T. (2012) Utilisation of pineapple leaf waste for plastic. Ind. Crop. Prod. 40, 55.

[13] Kumarasamy S., Shukur M. Zainol Abidin, Abu Bakar M.N., Wazid M.S., Mustal Z. and Anjang A. (2018) Effects of high and low temperature on the tensile strength of glass fiber reinforced polymer composites. IOP conference series: Materials Science and engineering, vol. 370, conference 1.

[14] Nadanthangam N., K, Karande, G.B Hadge, S.T Mheske and A.K. Bharimalla (2013) Enzyme/zncl pretreatment of short shape cotton fibers for energy reduction during nano fibrillation by refining process" world cotton research conference on technologies for property 2009.

[15] Saheb, D.N.and Jog, J.P (1999). Natural fiber polymer composites: A review. Adv. Polym. Technol. 18, 351-363.

[16] Satyanarayana, K.G.; Arizaga, G.G.C.; Wypych, F. (2009) Biodegradable composites based on lignocellulosic fibers-An overview. Prog. Polym. Sci., 34, 982102. 


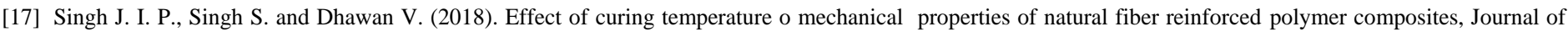
Natural fibers 15:5,

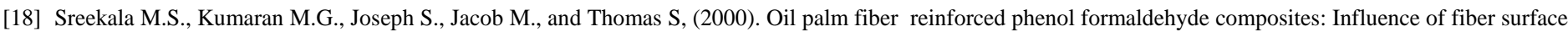
modifications on the mechanical performance. Appl. Compos. Mater., 7, 295-329.

[19] TAPPI T203 cm-99 TAPPI Test Method 1999 edition, for $\alpha$ - cellulose of pulp and wood.

[20] TAPPI T204 cm-17 TAPPI Test Method 2017 edition, for extractives of pulp and wood.

[21] TAPPI T222 cm-02 TAPPI Test Method Acid-insoluble Lignin in wood and pulp.

\section{AUTHORS}

First Author - Aneke N.A.G, Chemical Engineering Department, Enugu State University of Science and Technology, Enugu, Nigeria Second Author - Egbuna S.O, Chemical Engineering Department, Enugu State University of Science and Technology, Enugu, Nigeria

Third Author - Ejikeugwu N. L, Advance Manufacturing unit, Scientific Equipment Development Institute, Enugu, Nigeria Fourth Author - Omotiomo M, Chemical Engineering Department, Enugu State University of Science and Technology, Enugu, Nigeria 